\title{
Tackling limited spatial ability: lowering one barrier into STEM?
}

\author{
Chris Dawson \\ School of Education, University of Adelaide, Adelaide, Australia \\ For correspondence: chris.dawson@adelaide.edu.au
}

\begin{abstract}
Accumulated evidence indicates that low spatial ability makes a contribution, separate from levels of general or verbal intelligence, to the unlikelihood of students enrolling in, or succeeding in, STEM subjects. Further, there is a tendency for female students not to perform as well as males on some spatial tests, suggesting that this might be part of the reason for their under-representation in some STEM areas. However, the level of spatial ability has been shown to be related to both genetic and environmental factors, thereby suggesting that it can be improved with appropriate training.

Here I look at some of this background and prior research, including training studies, in several STEM subjects. Interestingly, as subject specific expertise develops, drawing on specific knowledge tends to replace the need for spatial thinking, so it is the negotiation of any initial spatial barrier into a subject which is crucial. To effect this, I outline a relatively new spatial categorisation which could be valuable for STEM teachers as a framework to help them guide their students through the early spatial demands of their own teaching subject(s).

Keywords: spatial ability, STEM, course selection, gender differences, spatial training
\end{abstract}

\section{Introduction}

There are no doubt a number of reasons why students choose not to enrol in STEM subjects (Science, Technology, Engineering, Mathematics), and why related careers are not chosen. As one of these, it has frequently been suggested that a student's weakness in spatial abilities makes a contribution. For instance, apriori, lack of spatial strengths might be detrimental when considering such things as the shapes and interactions of molecules in chemistry, when studying gearing in physics or engineering, in geometry, in earth science when visualising eclipses or diagrams illustrating change over time, and similarly in astronomy, and in biology the task of translating 2D images of cells to 3D mental representations. This relationship of spatial ability to entering STEM areas has been specifically examined by several researchers including Shea, Lubinski\& Benbow (2001) who monitored those students who had displayed extremely high mathematical ability (top 3\%) and found even within this group a wide range of spatial ability. Among them there was also a strong tendency for those with high spatial vs. verbal skills to be continuously involved in STEM areas, whereas those with the opposite pattern gravitated to careers in the humanities, social sciences, law etc. A large study by Wai, Lubinski, \& Benbow (2009) also provided support when it outlined evidence that, from bachelor through to doctorate levels, and also in several occupations, those in STEM areas showed greater levels of spatial ability than others in areas such as education and the humanities. Similarly, in chemistry Bodner \& McMillen (1986) identified a significant correlation between spatial ability and chemistry test performance, not only on clearly spatial tasks but, rather surprisingly, also in areas such as stoichiometric calculations. A similar study by Carter, LaRussa \& Bodner (1987) showed that scores on spatial tests were particularly correlated with success on those chemistry items that required students to analyse questions, or solve problems, rather than where only rote memory or algorithmic solutions were required. And in mathematics, Hegarty \& Kozhevnikov (1999) demonstrated a moderate correlation between spatial and mathematical abilities, with spatial ability 
correlating with mathematics scores on the Scholastic Achievement Test (SAT) and being a major predictor of mathematical ability after controlling for other factors such as general intelligence (Rohde \& Thompson, 2007). Thus, overall there is evidence that spatial abilityis a separate factor from general intelligence, with which it is not highly correlated (Rodan, Contreras, Elosúa, \& Gimeno, 2016), in both the selection of, and success in,STEM educational studies and careers.IndeedShea et al. (2001) suggested that, in line with other psychological studies (Lohman, 1994; Eysenck, 1996), the balance on the spatial vs. verbal bipolar dimension is more important than the mathematical vs. verbal. They also concluded that numbers of students with strong spatial skills are missing from STEM related directions becauseselection processes tend to see spatial skills as being of lower status than verbal and mathematical abilities, and only of value for technical subjects and occupations. Despite these findings, Hegarty, Crookes, Dara-Abrams \& Shipley (2010), using a self-report approach, found that STEM experts in different specialist areas rated their own spatial abilities at different levels, with geoscientists having the highest self-ratings while physicists, chemists and astronomers did not rate their spatial abilities particularly highly. However, this last finding might not be due to them actually having a lower level of spatial ability, but that these experts more commonly use alternative strategies when they tackle problems, as will be discussed later.

Unfortunately, there is a major difficulty when discussing spatial ability, and this is the lack of consistency in how it is defined and measured. Different classifications have been derived from factor analytic studies, one commonly used one proposing three separate components - spatial perception, spatial visualization, and mental rotation (Linn \& Petersen, 1985) each of which is supported by spatial working memory.To assess these, a range of different tasks have been developed including paper and pencil tasks, the manipulation of objects, and computer simulations, all of which are usually aimed at studying one aspect of spatial thinking: however mapping all of these onto a single agreed categorisation has currently proved impossible. Nevertheless, there appears to be aa level of agreement that 'spatial thinking should be considered a foundational cognitive skill' (Burte, Gardony, Hutton \& Taylor, 2017).

\section{Literature Review}

\section{Differences in spatial abilities}

Quite obviously, individuals will differ in their spatial abilities, and these differences have been noted as being of importance in STEM areas, though they have largely been neglected as an important ability during selection processes (except where, together with mathematics and verbal abilities, they form part of a general intelligence test). This has prompted a proposal that specific spatial testing should become part of STEM selection processes (Lubinski, 2010). In fact, following a demonstration of a correlation between spatial ability and surgical expertise, Wanzel, Hamstra, Anastakis, Matsumoto \& Cusimano (2002) had proposed that spatial ability might be used in the selection process for surgical residents, and this became the case with some dental schools (e.g. The University of Western Australia) assessing spatial thinking as a specific component of the selection process (Newcombe \& Shipley, 2015),

\section{Gender differences}

A particular focus has been on gender differences where females may perform at lower levels than males, and consistently so on mental rotation tasks. Thus Voyer, Voyer \& Bryden (1995) considered the effect sizes from 286 spatial tests and concluded that significant gender differences, favouring males, were most commonly found in mental rotation tasks, less so for spatial perception and rarely for spatial visualisation. Their additional analysis also suggested that, while gender differences are found on some tasks from an early age, the differences appeared to increase into adulthood. And more recent studies of undergraduates (Astur, Tropp, Sava, Constable \& Markus, 2004), and of adults (Parsons, Larson, Kratz, Thiebaux, Bluestein, Buckwalter \& Rizzo, 2004; Weiss et al, 2003) have shown 
significant gender differences, particularly on mental rotation tasks. Interestingly though, in a study by Maeda \& Yoon (2013) male superiority was only greater when strict time limits were applied, though Peters (2005) did not find any change to gender differences even with relaxed time limits.So it unclear whether performance is altered by the method of test administration.

Many of these gender-based studies have been conducted with adolescents and adults, and a suggestion has been made that the differences arise together with hormonal changes during adolescence (Maccoby \& Jacklin, 1974). And certainly there is evidence of some hormonal effects as Schöning et al. (2007) discovered when using fMRI to examine the effect of the concentration of hormones, such as oestradiol and testosterone, on brain activity as adult subjects undertook mental rotation tasks. However Levine, Huttenlocher, Taylor \& Langrock (1999) demonstrated that even for four year olds there were significant differences, favouring males, not only on mental rotation tasks, but also on translation items: they also cited several other studies showing gender differences at an early age. Later studies with six year olds (Tzuriel \& Egozi, 2010) and eight to ten year olds (Newhouse, Newhouse \& Astur, 2007) found significant gender differences on spatial tasks. Evidence such as this has led to the suggestion that prenatal hormonal effects, in particular from testosterone, are important, and both animal and human studies tend to support that view (Roof \& Havens, 1992; Grimshaw, Sitarenios \& Finegan, 1995). Nevertheless environmental effects are also important, and Jirout \& Newcombe (2015) demonstrated that early play with building blocks, which tends to be more common amongst boys, appears to be related to the spatial skills of 4-7 year olds. Thus, the whole issue of the relative importance of hormonal effects is still unclear (Miller \& Halpern, 2014).

More recently some studies have suggested that gender differences are reducing, and Rodan et al. (2016) found no significant gender differences on mental rotation tasks either before or after a training session in their sample of 14-15 year olds. One suggestion is that this change may be related to the relatively similar experiences both genders are now having with the electronic media, including gaming (Terlecki et al., 2011).

A recent comprehensive review of the area by Levine, Foley, Lourenco, Ehrlich \& Ratcliff (2016) summarises findings from investigations into sex differences in mental rotation, factors contributing to sex differences in spatial skill,and training studies aimed at reducing gaps between the sexes.Nevertheless, while gender differences are important and will be referred to again, there is considerable overlap between males and females, and it is the broad range of individual differences which needs to receive our fullest attention. And a major question is, what are the relative contributions from genetic makeup and from environmental factors?

\section{Nature or nurture?}

An important study by Tosto et al. (2014) of 4174 pairs of 12-year-old twins addressed this question finding that about a two thirds of the variation in spatial ability is explained by environmental factors. Implicit in that study is that spatial ability is potentially malleable.

However, a more recent study by Rimfeld et al. (2017) utilised data from a large number of twin pairs using a battery of different spatial tests (though these did not cover all areas, including mapping). Their results indicateda greater importance for the effect of a genetic component on general spatial ability $(69 \%)$, a smaller individual environmental component $(23 \%)$ and a smaller shared environmental component.(8\%), with these effects similar for both genders. However they were at pains to note that this only reflects the current state, and does not necessarily indicate that environmental changes through training might not have a significant effect on outcomes. They also note the apparent complexity of genetic influences on such things as general intelligence $(\mathrm{g})$ and on spatial ability where the likelihood is that the genetic contribution to these is generated from several, maybe hundreds, of genes, each making a small contribution. 
One suggestion for observed difference in performance has looked at differences in spatial working memory. The Baddeley \& Hitch (1974) model of working memory proposed two major slave systems, the phonological loop and the visuo-spatial sketchpad. The latter is a temporary and limited storehouse for holding visuo-spatial components. Because its limit on holding and manipulating individual components is very small, and varies between individuals, it can set restrictions on the spatial ability of an individual. Some degree of confirmation for this suggestion was found by Kaufman (2007) who examined differences in spatial working memory and identified significant differences between males and females, favouring males.

Other studies have focussed onphysiological differences such as the different morphologies of the corpus callosum (Kurth, Spencer, Hines \& Luders, 2018) and cerebral blood flow (Loftus, Jacobsen \& Wilson, 2018).

More recent developments in the use of fMRI, and other brain imaging techniques, have enabled light to be shed on the actual brain mechanisms and changes involved when undertaking spatial tasks. Studies have looked at the effects of such things as music, language, juggling and dance, though probably the most intensive have been on changes to the hippocampiof London taxi drivers. Over a period of about four years, trainee drivers learn the layout of London streets and to qualify are tested on their knowledge. While there have been several studies of brain changes, the controlled MRI longitudinal study of 79 trainees by Woollett \& Maguire (2011) is important. Of their trainees, 39 qualified, with the others failing or dropping out at different points. Their study indicated that there were no differences in knowledge or in hippocampal grey matter volume between the eventual passes, failures and controls at the beginning of the study. However, at the end there were significant increases in the grey matter volume of the posterior hippocampus for successful trainees, but not for failures or controls. There were also changes in spatial ability. While successful trainees had a greatly improved spatial representation of London streets, they performed less well than others on a complex figure test which assessed recall of visual material after a 30 minute time gap. Importantly, unlike many studies which only show a correlation between spatial ability and some other variable (with no clear findings about the direction of the relationship), studies such as those on bus drivers show a clear and direct relationship between the amount of training and the extent of related brain changes.

Studies of juggling training (Draganski et al., 2004) have also shown increases in grey matter, this time in the mid-temporal and left posterior intraparietal sulci, following training. However changes were partially reversed after a time period when juggling practice was stopped - possibly an indication of the 'use it or lose it' principle, and of competition for brain space by different tasks..

As Woollett \& Maguire (2001) noted that MRI studies in humans cannot directly identify the mechanism for these grey matter changes. However studies in animals, where experimentation is more manipulable, have been suggestive of several possible candidates, including neurogenesis, increasing dendritic arborisation, effects from glial cells and so on. They also note that it is possible that inherited genetic differences may enhance brain plasticity only in some people, indicating a possible epigenetic interaction between nature and nurture.

This implies that the separation of genetic and environmental effects is not easy, given that epigenetic effects imply possible interactions between the two. And, importantly, from the educator's perspective, the cause (or causes) is less important than the finding that there is an environmental component which opens the doorway to skill development.

\section{Use of different spatial strategies}

Interestingly there is evidence of different, but often equally successful, strategies being used to solve spatial problems. Much of this work has focussed on overall gender differences, however it is very probable thatindividuals from both genders will be using the different approaches. 
Using fMRI, Sundberg et al. (2000), Weiss et al. (2003) and Schöning et al. (2007) all showed that,when solving mental rotation problems, males tend to show predominantly parietal lobe activity, whereas females show more frontal lobe activation suggesting that different problem solving strategies are being used.Again gender differences were found by Hahn, Jansen \& Heil (2010). They examined the ability of pre-schoolers to mentally manipulate rotatingletters. While finding no gender differences in speed or accuracy, it was seen that boys' brain activity tended to be lateralised to the right hemisphere, whereas girls' brain activity was bilateralised.

Jordan, Wustenberg, Heinze, Peters \& Jäncke(2002) examined the brain activation patterns of males and females who had performed equally well on a mental rotation task. Their findings again showed that males and females tended to show different brain activation patterns which, they suggested, might be evidence of the use of different solution strategies, a finding which has may have significance for the teaching of STEM subjects.

Early work by Myers (1958) had foundsubjestschanging strategies as problems became more complex. With relatively simple rotational problems the tendency is to mentally rotate the whole object. However, with increasing problem complexity, analytic approaches which break down the object and look at its individual parts, were increasingly used, and which approach a subject has adopted is not obvious from their success or failure. That there are a range of strategies available for solving a particular mental rotation problem was demonstrated by Allen (1974). A group of University students recorded the strategies they used, and up to 20 different approaches were indicated for some rotational items. The more frequently used strategies, including mental rotation, were reported equally by males and females. However, it appeared that females tended to be less successful with this approach and, as a back-up, resorted to other strategies which included using analytic approaches, concrete aids, guessing and giving up. Overall the approaches of the males seemed to be more efficient and more geared to mental rotation.

In the specific area of chemistry, Stieff, Ryu, Dixon \& Hegarty (2012) observed some change in adopted strategies as University level learners became more experienced in a six-week intensive organic chemistry subject. While no deliberate attempt was made to teach particular strategies during this course, the lecturer did in fact use a variety of approaches during teaching. Student strategies at different points during the short course varied, and included mental rotation, drawing diagrams, using a spatial-analytic approach and applying algorithms. Of these mental rotation was the commonest approach used immediately after a topic had been taught, and this was still the case at the end of the course. However, actual numbers using the approach decreased and the number using diagrammatic or analytic approaches increased substantially, suggesting that as expertise develops more flexible strategy use also becomes available. The results also indicated that students with initially lower spatial ability were more likely to switch to alternative strategies, while those with high spatial ability tended to more consistently rely on this when solving problems. In line with this, females were more likely to shift to alternative strategies than males. Clearly then the ability to correctly answer the chemical problems depended not on spatial ability alone, but on the ability to select an alternativestrategy which the individual could utilise. And this ability seemed to arise with experience, as more potential strategies became available.

This increasing availability of different strategies, has been noted by Uttal \& Cohen (2012).They suggest spatial skills strongly predict which students will enter into STEM fields, and in the novice stages of learning spatial thinking is frequently called upon. However,with experience, learners become familiar with the types of problems in the area and are able to generalise rules and algorithms which allow solutions without any mental spatial manipulations. In consequence, because of the spatial need in the early stages, and the unavailability of alternative strategies, this lack may serve as 
a barrier into these subjects for those with lower spatial abilities, a group which usually contains more females than males.

In concordance with this notion of alternative strategies developing together with experience, it has been proposed that a mental manipulation strategy is the default position used both by novices and experts meeting new spatially-related problems. However as rule-based strategies are intuited with experience, experts tend to use these. Thus Schwartz \& Black (1996) noted that in the interpreting of gearing, learners began with a spatial approach which, with experience, tended to move toward more rule based strategies. However, when these did not work for novel problems, learners reverted back to spatial approaches.

Newhouse, Newhouse \& Astur (2007) proposed that at least part of the gender difference in navigation is most likely to be explained by the use of different strategies. In their spatial test, using a water maze task, it appeared that males favoured strategies related to distance and direction, whereas females tended to rely mainly on landmarks.

In 2012, Hambrick et al. outlined a 'circumvention-of-limits' hypothesis. The suggestion was that, as expertise develops, increasing domain specific knowledge reduces the need for spatial thinking - that is an individual student can gradually avoid the limits of his or her limited spatial ability. And Uttal \& Cohen (2012) suggest that, within the study of particular subject areas, there is usually not the need to use the type of content free spatial thinking assessed in spatial tests. Rather, at all times, thinking involves an intertwining of spatial thinking together with domain specific semantic knowledge, with the latter becoming more important with increasing study.

\section{Enhancing spatial abilities}

There is evidence that low spatial ability is related to lower enrolment into STEM subjects, and also to increased dropout rates following enrolment (Price, 2010; Min, Zhang, Long, Anderson, \& Ohland, 2011). However, differences in spatial ability appear to have a significant environmental component, so it is evident that the question of the value of spatial training arises, together withany effect that might have on enrolment into, and success in, STEM subjects. Indeed, there are many training studies reported in the literature some of which use subject-neutral spatial training, with dedicated and separate spatial coursework (Sorby, 2009a, 2009b). Others incorporatesubject-specific training regimes into the usual teaching program (e.g. Stieff, Dixon, Ryu, Kumi\& Hegarty, 2014). Within these, different formats have been used in training with changes from pencil and paper, through models, to computer based delivery and training through videogames and virtual reality (e.g. Rafi, Samsudin\& Said, 2008). In addition different amounts of time have been devoted to training. So to summarise, there has been very little standardisation in attempts at training.

\section{General spatial training}

The intention of some spatial training is to develop general spatial skills which will then transfer to other spatial tasks. This contrasts with a second approach which is to develop the necessary spatial skills for a subject area within that subject.

Wright, Thompson, Ganis, Newcombe, \& Kosslyn (2008) used daily training on computerised mental rotation and mental paper-folding tasks and found improvement in spatial skills, and that these skills transferred to other tasks, suggesting that learning was process, not task, based. Similarly Tzuriel \& Egozi (2010) demonstrated that for six year old children eight 45 minute instructive sessions focussing on looking at drawings, physically rotating them, taking different perspectives and discussing them in small groupings produced significant gains in mental rotation ability in both boys and girls. And as girls improved more than boys, it was also sufficient to eliminate gender differences which, the authors suggest, may have been there initially because the boys were more likely to use a more successful holistic mental rotation strategy, whereas girls tended to be more specific detail oriented. 
More recently the effects of videogame use on enhancing spatial skills has been investigated. Feng, Spence \& Pratt (2007) demonstrated that playing an action videogame reduced gender differences in mental rotation ability and removed differences in spatial attention. Terlecki, Newcombe \& Little (2008) found training on the videogame Tetris improved success on a mental rotation test, but so did solely repeating the test. Individuals progressed at different rates, and concern was expressed that the slow initial improvement of girls would negatively affect their willingness to persevere with such training. Rodan et al. (2016) also found a computerised mental rotation training program in a gametype format, and with instant feedback on responses, improved mental rotation skills. In the same vein, the use of a virtual reality format has been shown to enhance spatial ability, at least temporarily (Molina-Carmona, Pertegal-Felices, Jimeno-Morenilla\& Mora-Mora, 2018).

A review of the extant literature by Spence \& Feng (2010) of the effects of videogames on spatial cognition, focussed particularly on first-person shooter (FPS) games. It was extremely positive in its conclusions.

"Playing action games - particularly FPS games - produces improvement in sensory, perceptual, and spatial cognitive functions that are different from the expertise acquired in the game. ...... Furthermore, the improvements persist for a long time. These findings have profound scientific and educational implications" (p.102).

However a later review by Redick \& Webster (2014) was less enthusiastic in its conclusions.

Accordingly, we highlight a few studies that on the surface produce evidence for transfer of spatial abilities, but a closer look at the pattern of data does not reveal a clean interpretation of results (p.1).

A recent metaanalysis of available studies (Uttal \& Cohen,2012; Uttal, Meadow,Tipton, Hand, Alden, Warren \& Newcombe, 2013) found that training can be of value in improving spatial skills, and that there is evidence for the retention of these skills over a period of time, and also some transfer to nontrained tasks. Nevertheless results are contradictory and Miller\& Halpern (2013a), studying highly gifted students, collected evidence that 12 hours of spatial training reduced gender differences and improved mental rotation abilities.However,after an eight-month gap these training differences had almost disappeared with no positive effects on course grades, declared majors or physics self-efficacy. From a range of studies, it is suggestive that the effectiveness of general training studies may depend on the type of intervention and its length, as well as particular student characteristics. One point to note here is that the majority of the studies focus on success of the subjects on mental rotation tasks, partly because these consistently demonstrates gender differences, and also because this is seen as a high level spatial skill. Whether this encompasses all of the spatial skills needed in STEM subjects, or even whether it is representative of such skills, will be addressed later.

\section{Subject based findings}

A very large number of studies have looked at spatial requirements, availability and specific training in a variety of STEM subjects. While it is not possible to summarise all of these here, some of the findings which are more relevant to this paper are described.

\section{Geology}

Chadwick (1978) described the importance of the need for geologists to have the skills to"think in three dimensions, for visualizing shapes in the mind's eye, rotating, translating and shearing them, and for imagining complex changes over time in the form of a cinematographic visual image" (p.144). Kali \& Orion (1996) looked at the types of answers given by 16 year-olds to a series of diagrams testing their interpretation of geologic structures. The results appeared to show a distinct dichotomy in responses. While many of these were incorrect, one group of responses focussed totally on the 
exterior of the diagrams. A second group though gave what were called 'penetrative answers' where they attempted to visualise the interior structure of the representations, and this ability (not always practised successfully in that study) was deemed to be of great importance. A little later,Orion, BenChaim \& Kali (1997) demonstrated a high correlation between spatial visualisation and achievement, and particularly distinguished two types of topics: those which could be modelled using concrete objects and those which are more abstract. Significantly, they showed that, without any specific training, students' visualisation skills developed during the course, suggesting that what might be seen as an initial barrier to geological study was successfully negotiated during teaching.

\section{Chemistry}

Tuckey \& Selvaratnam (1993) took the position that a major problem is the linking of the 2-D presentations on paper to 3-D mental images and argued the need for this link to be consistently made throughout all forms of teaching.

Harle\& Towns (2010) indicated several areas of chemistry where skills in spatial thinking are important. They also proposed the need to incorporate assistance throughout a chemistry course in three different areas:

- explicitly articulation of three dimensional cues

- provision of ongoing instruction in molecular representation

- provision of visualisation resources for students to practice spatial ability skills

Importantly, they noted how the importance of mental rotation reduces as expertise develops, and instead content based analytical skills come to the forefront, and they particularly cited Mohler's (2008) proposal that there is a need to teach students to "strategically dissect spatial problems", that is to be able to adopt a more analytic rather than wholly mental manipulation approach.

Focussing especially on chemistry skills, Stieff, Dixon, Ryu, Kumi \& Hegarty (2014) investigated the effect of three different training regimes -an imagisticstrategy (using models and gestures to indicate spatial relationships), an analytic strategy (using only diagrams and disciplinary heuristics) and a combination of the two. Their findings showed that following analytic training these strategies were used more frequently when solving organic chemistry problems, though females were still more likely to use them than males. Also, while training in neither the imagisticnor the analytic strategy alone reduced the male advantage in problem solving, the combined strategy training eliminated it.

\section{Biology}

Macnab\& Johnstone (1990) examined the spatial skills of students from eight year-olds to adulthood, looking at primary students who had no formal biology training through to biology lecturers and researchers. Tests, which were not biological in nature but replicated the thinking involved in biology, included the ability to visualise a 2-D section taken from a cut surface of a 3-D diagram, to visualise a 3-D object from 2-D sections, and the ability to recognise an object when its orientation is changed. Results indicated that older respondents performed better than younger ones, biology students performed better than non-biology students, and some tasks proved more difficult than others with skills not developing in the three areas at the same rate, and with 3-D to 2-D skills being the latest to develop. The authors' final conclusion was that:

"It might be argued that the study of biology improved spatial skills, but what is equally probable is that those who did not have potential spatial ability would be unlikely to select the biological sciences, or, if they did opt for biology, their lack of success would deter them from continuing beyond a certain level." (p.40).

\section{Physics}

Miller \& Halpern (2013b) found that 12 hours of spatial training improved the spatial ability and physics test scores of high ability STEM undergraduate students over a control group. However, after a gap of eight months these differences had disappeared, and significant gender gaps, favouring 
males in both spatial skills and physics performance, were still present. Interpretation of these results is difficult, given that others have found stability in changes, however this may be partially due to the high ability cohort of students in this study. Miller and Halpern did suggest though that there might be a need for a more sustained period of intervention to help those with low spatial ability and to reduce gender gaps.

Kozhevnikov, Motes \& Hegarty (2007) investigated spatial visualisation in several kinematics problems including a hockey puck problem and a rocket problem. In each of these the object was described as moving in a straight line when a force was applied at right angles to that motion: students had then to predict the resultant motion. Two groups of students, who had been previously selected as high ability or low ability on spatial skills, responded. The group of low spatial ability respondents tended to focus only on motion in one direction, whereas high spatial ability respondents attempted to integrate the horizontal and vertical components. The authors suggest that, in combination with the results from their other experiments, this indicates that learners demonstrating low spatial ability have lower visuo-spatial working memory available and focus only on limited information, and this, combined perhaps with lower conceptual knowledge, results in the lower performance. Interestingly though, Kozhevnikov \& Thornton (2006) showed that the correlation between spatial ability and kinematics problem solving success disappeared during physics instruction, suggesting again that low spatial ability is of concern mainly at the early stages.

\section{Engineering}

Alias,Black \&Gray(2002) had first year engineering students carry out three types of spatial tasks over the course of a week and found some improvement in an engineering drawing test as compared to a control group.

Martin-Gutierrez (2010), in a short remedial training task, developed an augmented book which was designed to utilise 3-D virtual models. This augmented reality approach (AR) was designed to illustrate an interaction between the real world of objects and diagrams within a virtual world. Statistically significant improvements were found in mental rotation ability in the experimental group, but not in a control group.

Most important in this area are the continuing studies of Sorby and colleagues which developed within the engineering field initially (Sorby \& Baartmans, 2000), and then expanded outside of this. An early publication (Sorby, 1999) outlined the importance of spatial skills and suggested a strong need to gain more understanding of:

- what exactly are they?

- how do they develop?

- how do they interact?

- how are they used?

However, while some progress has been made here, much more is still to be learned.

In 2007, Sorby pointed out the underrepresentation of women in engineering and that, while special programs in mathematics and chemistry had been developed, particular assistance with spatial skills might also be needed. She noted that engineering has many 'gateways' including calculus, physics and chemistry, but that spatial skills might be another, largely unrecognised, one.

Over a period of time, and using several approaches, which included model building and sketching, a quite lengthy undergraduate course developed with lectures and computer laboratory work (Sorby, 2009a). Results of this showed that students with initially low spatial skills who undertook this course earned higher grades in introductory engineering, mathematics and science courses.Further the 
retention rates of women improved, though there was no change for men. In particular the activity of formally sketching objects within the training course was seen to be of high importance.

A related course used with middle school students (years7 and 8) (Sorby, 2009b) using multimedia software combined with a workbook showed student increases in spatial ability with girls improving more than boys, thereby reducing the gender gap. Importantly also, girls who undertook this course were more likely to enrol in further mathematics and science courses. However, when the same course was used with high school students, there was no increased uptake of science or mathematics courses, suggesting middle school is the best time to have an effect. Possibly by high school students have already firmed up on their interests and future plans.

In 2013, Sorby, Casey, Veurink \& Dulaneynoted that females who have selected engineering tend to have poorer spatial skills than their male counterparts, but she collected evidence supporting theearlier training studies and demonstrated that students who studied the spatial skills course not only improved on spatial skills, but also scored higher than other students in a calculus course.

While not directly involved in a training regime, Mohler (2008) looked at high and low spatial achievers in an engineering graphics course and interviewed them to determine how they went about solving certain spatial tasks. Differences noted between the high and low achievers were that high ability students more commonly:

- broke down spatial problems (mental deconstruction)

- worked across different views

- double checked their work

These results suggest that, while spatial skills might be important, the high achievers also tended to utilise a wider range of cognitive and metacognitive skills.

\section{Mathematics}

Guven\& Kosa (2008) usedspatial skill training software over a period of eight weeks with student mathematics teachers following which improvement in spatial ability was shown. Similarly other authors have reported training regimes which increase spatial ability and at the same time improve mathematical attitudes or ability (Cakmak, Isiksal \& Koc, 2014; Cheng \& Mix, 2014). However a different aspect was proposed and tested (Maloney, Waechter, Risko \& Fugelsang, 2012) when the authors looked at the relationship between mathematics anxiety (which is greater for women) and mathematical skills. Results of their work suggested that this relationship is mediated by spatial processing ability. And, because gender differences in spatial ability are seen as early as five months of age (Moore \& Johnson, 2008), it seems quite probable that early spatial difficulties result in difficulties with some mathematical concepts, and this, in turn, increases mathematics anxiety, which, in turn, is likely to turn such learners away from mathematical studies.

\section{Surgery}

While not directly related to STEM study at the school level, it is the case that a grounding in scientific studies is necessary for both medical training and later surgical training. And it certainly would appear that high level spatial skills might be necessary for surgeons. There have been a number of studies of this, and Keehner et al. (2004) found that with less experienced surgeons there was a correlation between results on spatial tests and operating skills.However, this relationship was not found for more experienced surgeons, and it appears that, while some with lower spatial ability might take longer to reach acceptable skill levels, they are still capable of doing so, and might do so more quickly with focussed training. On the other hand, Leff, Leong, Guang-Zhong\&Darzi (2008) saw no evidence for relating surgical skill to mental rotation success. 
Thus, as in other areas, it is quite possible that entry into the STEM courses necessary to proceed into medical areas can be limited by weaker spatial skills. But it also seems that once initial barriers are crossed, and subject based expertise develops, spatial skills become less important.

\section{Overall}

From the brief summaries above, it appearsthat in several of these STEM areas, there is evidence that initial lack of spatial ability may form a barrier to success. However, this barrier can be broken down by appropriate spatial training in the early stages, with the amount of improvement likely be related to its relevance and the time spent on it. Nevertheless, hard evidence for definite links between any such improvement and improvements in STEM course enrolments and success is patchy and, while suggestive, it is certainly not conclusive, because most studies have been correlational and do not show the direction of interactions.

A further problem is the differential effect training may have. Thus Hoffler and Leutner (2011) found that learners with low spatial ability reacted differently to sessions with static pictures and those with dynamic displays, learning more from the latter, whereas for high spatial ability learners there was no difference. In contrast, Lee, Wong \& Fung (2010) found that it was learners with initially high spatial skills who learned more from active experiences.

Because the various studies referred to above, and the many others, have been conducted independently, using different ages and abilities of students, different training regimes, and different means of assessing spatial skills, a clear picture of what can be done has not emerged, just as a clear structure of what is meant by spatial skills is not agreed. What seems to be evident though is that spatial skills are malleable and they therefore can be improved.

\section{Towards a solution}

While the area is complex with few indisputable conclusions, a recent publication (Newcombe \& Shipley, 2015) drew attention to a proposal for a new typology of spatial skillwhich may be of value to educators. They proposed four categories: intrinsic-static, intrinsic-dynamic, extrinsic-static and extrinsic-dynamic, where the intrinsic skills are related to spatial features of individual objects when static or when transformed in some way. Extrinsic skills are instead related to how the object sits in relation to other objects around (static) and how these relations change as objects are moved (dynamic). The authors claim that this typology can accommodate all aspects of the spatial skill literature.

The significance of this from a teacher/lecturer point of view is that it provides a more straightforward way of categorising the specific spatial skills required for each topic in each teaching subject, and is therefore suggestive of the types of training which might be most profitably adopted. Some possible examples of each of these categories for two different STEM subjects are given in Table 1.

Table 1. Examples of spatial skills needed in two subject areas.

Chemistry Biology

Intrinsic Static The 3-D implications of various The 3-D implications of typesof 2-D representations of the 2-D representation of a molecule the double helix

Intrinsic - Dynamic Comparison of a chiral Unzipping of the double helix
molecule with one of the same during mitosis
or different handedness




$\begin{array}{ccc}\text { Extrinsic }- \text { Static } & \text { Reaction mechanisms - } & \text { Structure of cell and spatial } \\ \text { initial spatial organisation } & \text { relationship of the components }\end{array}$

Extrinsic-Dynamic Reaction mechanisms - spatial
$\begin{gathered}\text { 3-D understanding of stages } \\ \text { changes during reaction }\end{gathered}$

RNA to protein synthesis

If, indeed, this is a useful view of how spatial tasks might be categorised, it may be of value to look at the various spatial tests which have been used to see how they fit into these categories, and to determine which of them are more appropriate for identifying the level of skills required in particular STEM subject areas. Literature analysis shows that by far the most common test used is mental rotation of a single object (intrinsic/dynamic), however it is evident that other spatial skills might be best assessed by other tests. A superficial examination of these tests seems to indicate each of these broad component skills could be assessed by using different types of test items. Thus the spatial perception test appears to assess the intrinsic/static dimension, mental rotation the intrinsic/dynamic, spatial visualisation the extrinsic/static (e.g. embedded figures items) and extrinsic/dynamic (e.g. paper folding items). Possibly there would be some value in trying to tie together the skills involved in these tests with the subject-specific skills required in each STEM area.

\section{What can parents, carers and early childhood educators do?}

Spatial differences between individuals and between genders appear at an early age with researchers attributingpart of the difference to genetics and part to experience.

Examining gender differences in experience, there is evidence of overall differences between boys and girls in the toys they prefer, the way they spend their leisure time and the extent, and type, of computer use they engage in. Interestingly both monkey and human studies have shown differences in toy preference between males and females from an early age. Thus a study with 3-8 month old infants showed boys tended to give more attention to a truck than a doll, with this being reversed for girls (Alexander, Wilcox \& Woods, 2009), suggesting some initial genetic or very early environmental effect. One influencemay be prenatal exposure to androgens, and indeed it has been shown that girls exposed to high levels of androgens before birth also show an increased interest in boys' toys as opposed to girls' toys. Other studies have examined the effect of testosterone levels in early infancy and again find a relationship between these and toy preference (Lamminmäkiet al., 2012).

In addition to early biochemical influences, there is evidence that parents and carers often encourage play with gender-typical toys, with this effect being stronger for boys than for girls, and this may be reflected in later preferences. In one study of older children (5-13 year olds), the top three toy preferences for boys were manipulative toys, vehicles and action figures. For girls the top three were dolls, stuffed animals and educational activities (Cherney\& London, 2006). This certainly suggests that different toys and playing styles might be involved in differential development of skills and interests, including spatial skills. More recent studies have indicated the greater involvement in video games by boys, and the links to spatial skills has been noted (Baenninger \& Newcombe, 1989).

However, while such gender differences are important, differences which may be summarised as a 'thing orientation' of boys and 'people orientation' of girls,individual differences within genders must be recognised. Gender differences are statistical showing overall trends only, and patterns are not the same for all boys or for all girls, and the spread within each group can be large.

Much can be done for spatial training in the early years, not by trying to force 'boys' toys' on girls, but by giving all children a wide range of early experiences includingboth sport and recreationalactivities with a spatial component. 


\section{What can a STEM teacher do?}

Spatial demands of science are perhaps greater than one might initially think. My recent analysis of a series of textbooks aimed at Years 8-10, indicated that more than half the topics made some spatial demands. Though some of these might seem trivial to many of us, they may not be so for some students. Below are a few examples, though their actual classification according to the Newcombe and Shipley (2015) classification above is not always clear and depends on the specific useage at the time. For instance, the arrangement within an electrical circuit can be seen as extrinsic/static, but when talking of current flow, there is a dynamic element. In any case, whether one accepts the Newcombe and Shipley categorisation, it is clear that there is a spatial demand of some sort within many topic areas.

Intrinsic/Static. Molecular structure, Soil profiles, Folding and faulting,

Intrinsic/Dynamic. Mammalian systems (e.g. circulatory system), Transmission of waves, Speed, Acceleration.

Extrinsic/Static Mammalian systems (bones and muscles), Magnetic fields.Electrical circuits.

Extrinsic/Dynamic Day/night, Seasons, Eclipses, Levers, Pulleys.

If spatial ability is recognised as setting some limit on which students progress into STEM areas, teachers need to take care to strengthen their students' spatial skills. Such intervention may be most needed at the primary and early secondary levels as Sorby (2009b) determined her general training course introduced to upper high school students appeared to be too late to change their STEM related intentions.

Focussing on spatial requirements must be done thoughtfully. Because STEM teachers have both the requisite conceptual knowledge andspatial expertise; many of their operations in the classroom are automatic,and place little demand on their working memory or on specific spatial skills. However, their students are in a very different position. They may be still struggling at the novice level with limited working memory, limited conceptual knowledge, possibly limited spatial skills and, for them, nothing is automatic.

Once abelief in the importance of the lack of spatial skill development as a hurdle early in STEM courses is accepted, there are two potential approaches. The first would be to devise a content free spatial skills course to develop a range of abilities, with the assumption that these will transfer, when needed, into a range of STEM areas. The second would be for STEM teachers in each subject area to consistently introduceany spatially dependent material in a way that learners meet, and gain ample experience and practice with, a variety of ways of looking at, and working with, the material (e.g. 2-D diagrams, drawing in 2-D and 3-D, 3-D models, model making, computer simulations and so on) and switching between different forms. For this the spatial categorisation of Newcombe \& Shipley (2015) might be useful to enable teachers to specifically focus on the type of spatial skill required for a particular topic. In addition assistance needs to be given in showing any different discipline specific ways of tackling specific issues, questions or problems using approaches where there is a much lesser need for applying spatial skills. Of these alternative approaches, the introduction of a general spatial trainingprogram has clear logistical problems related to timetabling in schools, but the second is possible without it making agreat negative impact on existing practice.

So the first important step is the teacher's awareness of the potential effect of widely differing individual spatial skills, including the possibly overall lower spatial ability of girls, on the progression into STEM areas. If a teacher recognises that hurdlescan arise, not only due to general intelligence levels, or from mathematical ability, but alsofrom the finding that spatial ability is a separate and important issue, then teaching approaches can follow. 
Initially learners might readily handlesimple cases using both physical and mental manipulations, but as more complex areas are investigated these maybe out of reach of some students' spatial abilities and the visuo-spatial component of working memory. Here then, alternative strategies need to be made available, including an analytic strategy where the spatialtaskis broken into smaller pieces which can be tackled separately(possibly using pen and pencil support) - a strategy that many girls, and boys with lower spatial ability, tend toward naturally on rotation problems, though not always successfully.

As an example from organic chemistry, molecular and structural formulae can be represented in quite different ways (see below for four examples of the same molecule, and there are many more depending on which bonds and which atoms one chooses to show), and are usually drawn fairly roughly (as below) on the whiteboard.From these, the similarities between them, and the spatial arrangement of atoms they represent, can present an immediate problem for novice students as each mayinitially be seen as a quite different compound, and swinging between them can place a big demand on working memory. To the expert chemist, though,such images are easily interchangeable and seeing each in 3-D, and handling any change from one to another is automatic.

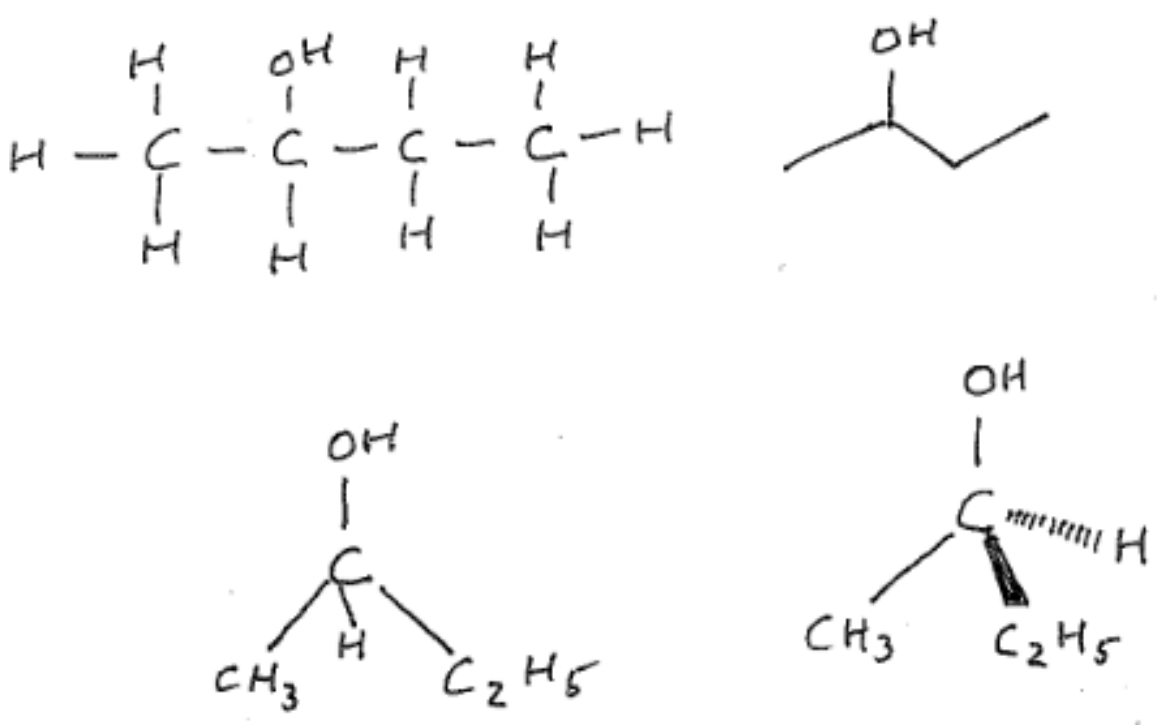

Especially difficult is interpreting chiral carbon atoms.and their handedness. Determining whether two representations are identical or mirror images can initially require a great deal of spatial processing, though later rules (e.g. Cahn-Ingold-Prelog) enable these problems to be tackled analytically.

Working with these involves both the intrinsic-static and intrinsic-dynamic categories of Newcombe \& Shipley (2015), and they can be put into context by using physical 3-D models which students can manipulate, and by the use of one of the YouTube video presentations on chirality. Further complexities, which move into the extrinsic modes, would need to be brought into play when chemical reactions are considered. Nevertheless, the core to such trainingmust be the students' continuingand regular practice with a variety of representations, including pencil and paper drawings, together with practice in changing representation.

Importantly, it is the lower spatial ability students who appear to benefit most from the provision of such assistance. High spatial ability students are able to use their abilities to handle more complex spatial relationships, but low spatial ability is a handicap and, possibly, a stopping point for others. As Barrett\& Hegarty (2016) found, the provision of stereo images, versus only mono images) had no 
effect on the success of students with high spatial ability, but were of great benefit to those of low ability.

\section{Conclusion}

Evidence has accumulated that a lack of spatial competency can form a barrier into making a success of STEM subjects. This is of particular importance in the early stages of study when spatial thinking is more necessary, and before decisions about whether to go on to further study are being made.Of course, low spatial ability is not the only barrier to successful STEM study, but it does appear to be an additional independent and important one. However, the barriercan almost certainly be loweredproviding that sufficient attention is paid to the difficulties students can experience. Thorough analysis of the spatial components of the subject, together with addressing, and practising, these carefully in the classroom, together with providing alternative strategies to understanding, should enable more learners to circumventany initial handicap of low spatial skills. And that could mean more students, including more female students, heading in the STEM direction.

\section{References}

Alexander, G, M., Wilcox, T,„\& Woods, R. (2009), Sex differences in infants' visual interest in toys. Archives of Sexual Behavior, $38(3), 427-433$.

Alias, M., Black, T. R., \&Gray, D. E. (2002). Effect of instructions on spatial visualisation ability in civil engineering students. International Education Journal, 3(1), 1-12.

Allen, M. J. (1974). Sex differences in spatial problem-solving styles. Perceptual \& Motor Skills, 39, 843-846.

Astur, R. S., Tropp, J., Sava, S., Constable, R. T. \& Markus, E. J. (2004). Sex differences and correlations in a virtual Morris water task, a virtual radial arm maze, and mental rotation. Behavioural Brain Research, 151, 103-115.

Baddeley, A.D., \& Hitch, G. (1974). Working memory. In G.H. Bower (Ed.), The psychology of learning and motivation: Advances in research and theory (Vol. 8, pp. 47-89). New York: Academic Press.

Baenninger, M. \& Newcombe, N. (1989). The role of experience in spatial test performance: A meta-analysis. Sex Roles, 20(5), 327-344.Barrett, T. J., \& Hegarty, M. (2016). Effects of interface and spatial ability on manipulation of virtual models in a STEM domain. Computers in Human Behavior, 65, 220-231.

Bodner, G. M., EMcMillen, T. L. B. (1986). Cognitive \& restructuring as the first step in problem solving. Journal of Research in Science Teaching, 23, 727-738.

Burte, H., Gardony, A., Hutton, A., \& Taylor, H. (2017). Think3d!: Improving mathematicslearning through embodied spatial training. Cognitive Research: Principles andImplications, 2, 1-18.

Cakmak, S., Isiksal, M., \&Koc, Y. (2014). Investigating effect of origami-based instruction on elementary students' spatial skills and perceptions. The Journal of Educational Research, 107, 59-68.

Carter, C. S., LaRussa, M. A., \&Bodner, G. M. (1987). A Study of Two Measures of Spatial Ability as Predictors of Success in Different Levels of General Chemistry. Journal of Research in Science Teaching, 24, 645-657.

Chadwick, P. (1978). Some aspects of the development of geological thinking. Journal of Geology Teaching, 3, 142-148.

Cheng, Y-L., \& Mix, K.S. (2014). Spatial training improves children's mathematical ability. Journal of Cognition and Development, 15(1), 2-11.

Cherney, I. D., \& London, K. (2006). Gender-linked differences in the toys, television shows, computer games, and outdoor activities of 5- to 13-year-old children.Sex Roles, 54: 717-726.

Draganski, B., Gaser, C., Busch, V., Schuierer, G., Bogdahn, U. \& May, A. (2004). Neuroplasticity: Changes in grey matter induced by training. Nature, $427,311-312$.

Eysenck, H. J. (1996). Genius: the natural history of creativity. Cambridge; New York: Cambridge University Press.

Feng, J., Spence, I., \&Pratt, J.. (2007). Playing an action video game reduces gender differences in spatial cognition.Psychological Science, 18(10), 850-855.

Grimshaw, G.M., Sitarenios, G. \& Finegan, J. A. (1995). Mental rotation at 7 years: relations with prenatal testosterone levels and spatial play experience. Brain Cognition, 29(1), 85-100.

Guven, B. \& Kosa, T. (2008). The effect of dynamic geometry software on student mathematics teachers' spatial visualisation skills. The Turkish Online Journal of Educational Technology, 7(4), 100-107.

Hahn, N., Jansen, P., \& Heil, M. (2010). Preschoolers' mental rotation of letters: Sex differences in hemispheric asymmetry.Cognitive Neuroscience, 1(4), 261-267.

Hambrick, D. Z., Libarkin, J. C., Petcovic, H. L., Baker, K. M., Elkins, J., Callahan, C. N., ....\&LaDue, N. D. (2012). A test of the circumvention-of-limits hypothesis in scientific problemsolving: The case of geological bedrock mapping. Journal of Experimental Psychology: General, 141(3), 397-403.

Harle, M., \& Towns, M. (2010). A review of spatial ability literature, its connection to chemistry, and implications for instruction. Journal of Chemical Education, 88(3), 351-360. 
Hegarty, M., Crookes, R. D., Dara-Abrams, D \& Shipley, T. F. (2010). Do all science disciplines rely on spatial abilities? Preliminary evidence from self-report questionnaires. In: C. Holscher, T. F. Shipley, M. Olivetti Belardinelli, J. A. Bateman, and N. S. Newcombe. (Eds.) Spatial cognition VII. LNCS, vol.6222, pp. 85-94. Springer: Heidelberg.

Hegarty, M. \& Kozhevnikov, M. (1999). Types of visual-spatial representations and mathematical problem solving. Journal of Educational Psychology, 91(4), 684-689.

Hegarty, M., Keehner, M., Cohen, C., Montello, D. R., \&Lippa, Y. (2007). The role of spatial cognition in medicine: applications for selecting and training professionals. In Applied Spatial Cognition, G. L. Allen, Ed., Erlbaum, Mahwah, NJ.

Hoffler, T. N., \&Leutner, D. (2011). The role of spatial ability in learning from instructional animations - Evidence for an ability-as-compensator hypothesis.Computers in Human Behavior, 27(1), 209-216.

Jirout, J. J., \& Newcombe, N. S. (2015). Building blocks for developing spatial skills. Evidence from a large, representative U.S. sample. Psychological Science, 26(3), 302-310.

Jordan, K.,Wüstenberg, T.,Heinze, H.J.,Peters, M., \&Jäncke, L.(2002). Women and men exhibit different cortical activation patterns during mental rotation tasks.Neuropsychologia, 40(13):2397-408.

Kali, Y., \& Orion, N. (1996). Spatial abilities of high-school students in the perception of geologic structures. Journal of Research in Science Teaching. 33, 369-391.

Kaufman, S. B. (2007). Sex differences in mental rotation and spatial visualization ability: Can they be accounted for by differences in working memory capacity? Intelligence 35, 211-223.

Keehner, M., Tendick, F., Meng, M. V., Anwar, H. P., Hegarty, M., Stoller, M. L., \& Duh, Q. Y. (2004). Spatial ability, experience, and skill in laparoscopic surgery. American Journal of Surgery, 188(1), 71-75.

Kozhevnikov, M. \& Thornton, R. (2006). Real-time data display, spatial visualization ability, and learning force and motion concepts. Journal of Science Education and Technology, 15, 113-134.

Kozhevnikov, M., Motes, M. A. \& Hegarty, M. (2007). Spatial visualization in physics problem solving. Cognitive Science, 31, 549-579.

Kurth, F., Spencer, D., Hines, M., \&Luders, E. (2018). Sex differences in associations between spatial ability and corpus callosum morphology.Journal of Neuroscience Research, 96 (8), 1380-1387.

Lamminmäki, A., Hines, M., Kuiri-Hänninen, T., Kilpeläinen, L, Dunkel, L., \&Sankilampi, U. (2012). Testosterone measured in infancy predicts subsequent sex-typed behavior in boys and in girls. Hormones and Behavior, 61(4), 611-616.

Lee, E. A-L., Wong, K. W., \& Fung, C. C. (2010). How does desktop virtual reality enhance learning outcomes? A structural equation modeling approach. Computers \& Education, 55(4), 1424-1442.

Leff, D. R., Leong, J., Guang-Zhong, Y., \&Darzi, M. D. (2008). Visuo-spatial ability and fMRI cortical activation in surgery residents. The American Journal of Surgery, 195(1), 138.

Levine, S. C., Huttenlocher, J., Taylor, A., \& Langrock, A. (1999). Early sex differences in spatial skill. Developmental Psychology, 35(4), 940-949.

Levine, S., Foley, A., Lourenco, S., Ehrlich, S. \& Ratcliff, K. (2016). Sex differences in spatial cognition: advancing the conversation. Cognitive Science, 7, 127-155.

Linn, M. C. \& Petersen, A. C. (1985). Emergence and characterization of sex differences in spatial ability: a meta-analysis. Child Development, 56(6), 1479-1498.

Loftus, J. J., Jacobsen, M. ,\& Wilson, T. D. (2018).The relationship between spatial ability, cerebral blood flow and learning with dynamic images: A transcranial Doppler ultrasonography study. Medical Teacher, 40 (2), 174-180.

Lohman, D. F. (1994). Spatially gifted, verbally inconvenienced. In N. Colangelo, S. G. Assouline\& D. L Ambroson (Eds.), Jocelyn Wallace National Research Symposium on Talent Development (2nded., pp. 251-264). Dayton: Ohio Psychology Press.

Lubinski, D. (2010). Spatial ability and STEM: A sleeping giant for talent identification and development. Personality and Individual Differences, 49, 344-351.

Maccoby, E., \&Jacklin, C. (1974). The psychology of sex differences. Pao Alto, CA: Stanford University Press.

Macnab, W. \& Johnstone, A. H. (1990). Spatial skills which contribute to competence in the biological sciences. Journal of Biological Education, 24(1), 37-41.

Maeda, Y. \& Yoon, S. Y. (2013).A meta-analysis on gender differences in mental rotation Ability measured by the Purdue spatial visualization tests: visualization of rotations (PSVT:R). Educational Psychology Review, 25, (1), 69-94.

Maloney, E. A.., Waechter, S., Risko, E. F. \& Fugelsang, J. A. (2012) Reducing the sex difference in math anxiety: The role of spatial processing ability. Learning and Individual Differences, 22, 380-384.

Martin-Gutierrez, J., Saorin, J. L., Contero, M., Alcaniz, M., Perez-Lopez, D. C. \& Ortega, M. (2010). Design and validation of an augmented reality for spatial abilities development in engineering students. Computer \& Graphics, 34 (1), 77-91.

Miller, D. I. \& Halpern, D. F. (2013a). spatial thinking in physics: longitudinal impacts of 3-D spatial training. Learning and Individual Differences, 26, 141-152.

Miller, D.I., \& Halpern, D.F. (2013b). Can spatial training improve long-term outcomes for gifted STEM undergraduates? Learning and IndividualDifferences,26, 141-152.

Miller, D. I. \& Halpern, D. F. (2014). The new science of cognitive sex differences. Trends in Cognitive Science, 18(1), 37-45.

Min, Y., Zhang, G., Long, R., Anderson, T. J., \&Ohland, M. W. (2011). Nonparametricsurvival analysis of the loss rate of undergraduate engineering students. Journal of EngineeringEducation, 2, 349e373.

Mohler, J. L. (2008). A review of spatial ability research. Engineering Design Graphics Journal, 72(3), 19-30.

Moore, D. S. \& Johnson, S. P. (2008). Mental rotation in human infants: A sex difference. Psychological Science, 19, 1063-1066.

Molina-Carmona, R., Pertegal-Felices, M. L., Jimeno-Morenilla, A., \& Mora-Mora, H. (2018). Virtual Reality Learning Activities for Multimedia Students to Enhance Spatial Ability. Sustainability, 10 (4), 1074 - 1087. 
Myers, C. T. (1958). Some observations of problem solving in spatial relations tests (ETS RB 58-16); Educational Testing Service: Princeton, NJ.

Newcombe, N.S.\& Shipley, T.F. (2015). Thinking about spatial thinking: New typology, new assessments. In J. S. Gero (Ed.), Studying visual and spatial reasoning for design creativity 179-192. Springer Science+Business Media Dordrecht.

Newhouse, P., Newhouse, C, \&Astur, R. S. (2007). Sex differences in visual-spatial learning using a virtual water maze in prepubertal children.Behavioural Brain Research, 183(1), 1-7.

Orion, N., Ben-Chaim, D., \&Kali, Y. (1997). Relationship between earth science education and spatial visualization. Journal of Geoscience Education, 45, 129-132.

Parsons, T. D., Larson, P., Kratz, K., Thiebaux, M., Bluestain, B., Buckwalter, J. G. \& Rizzo, A. (2004). Sex differences in mental rotation and spatial rotation in a virtual environment. Neuropsychologia, 42 (4), 555-562.

Peters, M. (2005). Sex differences and the factor of time in solving Vandenberg and Kuse mental rotation problems.Brain and Cognition, 57 (2), 176-184.

Price, J. (2010). The effect of instructor race and gender on student persistence in STEM

fields. Economics of Education Review, 29, 901e910.

Rafi, A., Samsudin, K. A. \& Said, C.S. (2008). Training in spatial visualization: The effects of training method and gender. Educational Technology \& Society, 11(3), 127-140.

Redick, T. S. \&Webster, S. B. (2014). Videogame interventions and spatial ability interactions. Frontiers in Human Neuroscience, 8 (183), 1-5.

Rimfeld et al. (2017). Phenotypic and genetic evidence for a unifactorial structure of spatial abilities. Proceedings of the National Academy of Sciences, 114(10), 2777-2782.

Rodán,A., Contreras,M. J., Elosúa, M. R.,\&Gimeno' P. (2016). Experimental but not sex differences of a mental rotation training program on adolescents. Frontiers of Psychology, 7, 1050, 1-12.

Rohde, T. E., \& Thompson, L. A. (2007). Predicting academic achievement with cognitive ability. Intelligence, 35, 83-92.

Roof, R. L.,\& Havens, M. D. (1992). Testosterone improves maze performance and induces development of a male hippocampus in females. Brain Research, 572, 310-313.

Schöning, S., Engelien, A., Kugel, H., Schafer, S., Schiffbauer, H., Zwitserlood, P . . . . \& Konrad, C. (2007). Functional anatomy of visuo-spatial working memory during mental rotation is influenced by sex, menstrual cycle, and sex steroid hormones. Neuropsychologia,45(14), 3203-3214.

Schwartz, D. L., \& Black, J. B. (1996). Shuttling between depictive models and abstract rules: Induction and fallback. Cognitive Science, 20, 457-497

Shea, D L., Lubinski, D., \& Benbow, C. P.(2001). Importance of Assessing Spatial Ability in Intellectually Talented YoungAdolescents: A 20-Year Longitudinal Study. Journal ofEducational Psychology, 93(3), 604-614.

Sorby, S.A. (1999). Developing 3-D spatial visualization skills, The Engineering Design Graphics Journal, 63 (2), 21-32.

Sorby, S. A. (2007) Developing 3D spatial skills for engineering students. Australasian Journal of Engineering Education, 13:1, 1-11.

Sorby, S.A. \&Baartmans, B.J. (2000). The development and assessment of a course for enhancing the 3-D spatial visualization skills of first year engineering students. Journal of Engineering Education, July, 301-307.

Sorby, S. A. (2009a). Educational research in developing 3-D spatial skills for engineering

students. International Journal of Science Education, 31(3), 459-480.

Sorby, S. (2009b). Developing spatial cognitive skills among middle school students. Cognitive Processing, 10(Suppl. 2), 312 e315.

Sorby, S., Casey, B. M., Veurink, N., \&Dulaney, A. (2013).The role of spatial training in improving spatial and calculus performance in engineering students. Learning and Individual Differences 26:20-29.

Spence, I. \&Feng, J. (2010). Videogames and spatial cognition. Review of General Psychology, 14(2), 92-104.

Stieff, M. (2007). Mental rotation and diagrammatic reasoning in science. Learning and Instruction, 17(2), 219-234.

Stieff, M., Ryu, M., Dixon, B., \& Hegarty, M. (2012). The role of spatial ability and strategy preference for spatial problem solving in chemistry. Journal of Chemical Education, 89, 854-859.

Stieff, M., Dixon, B. L., Ryu, M., Kumi.,B. C., \& Hegarty, M. (2014). Strategy training eliminates sex differences in spatial problem solving in a STEM domain. Journal of Educational Psychology, 106(2), 390-402.

Sundberg, H., Roscher, B. E., Smievoll, A. I., Hugdahl, K., Thomsen, T., Lundervold, A., .....\& Ersland, L. (2000). Functional magnetic resonance imaging (fMRI) study of sex differences in amental rotation task.Medical Science Monitor,6(6), 11861196.

Tan, U., Okuyan, M., Bayraktar, T., \& Akgun, A. (2003). Covariation of sex differences in mental rotation with body size. Perceptual Motor Skills, 96(1), 137-144.

Tan, O., Okuyan, M., Albayrak, T. \& Ahmet, A. (2003). Sex differences in verbal and spatial ability reconsidered in relation to body size, lung volume and sex hormones. Perceptual and Motor Skills, 96, 1347-1360.

Terlecki, M., Brown, J., Harner-Steciw, L., Irvin-Hannum, J., Marchetto-Ryan, N., Ruhl, L., \&Wiggins, J. (2011). Sex Differences and Similarities in Video Game Experience, Preferences, and Self-Efficacy: Implications for the Gaming Industry. Current Psychology, 30 (1), 22-33.

Terlecki, M. S., Newcombe, N. S. \& Little, M. (2008). Durable and generalized effects of spatial experience on mental rotation: gender differences in growth patterns. Applied Cognitive Psychology, 22(7), 996-1013.

Tosto, M. G., Hanscombe, K. B., ......\&Kovas, Y. (2014). Why do spatial abiliites predict mathematical performance?.Developmental Science, 17(3), 462-470.

Tuckey, H., \& Selvaratnam, M. (1993). Studies involving three-dimensional visualisation skills in chemistry: a review. Studies in Science Education, 21, 99-121. 
Tzuriel, D., \&Egozi, G. (2010). Gender differences in spatial ability of young children: The effects of training and processing strategies. Child Development, 81(5), 1417-1430.

Uttal, D. H., Meadow, N. G., Tipton, E., Hand, L. L., Alden, A. R., Warren, C. \& Newcombe, N. S. (2013). The Malleability of Spatial Skills: A Meta-Analysis of Training Studies. Psychological Bulletin 139(2), 352-402.

Uttal, D. H. \& Cohen, C. A. (2012). Chapter 4 - Spatial thinking and STEM education: when, why and how? Psychology of Learning and Motivation, 12, 147-181.

Voyer, D., Voyer, S. \& Bryden, M. P. (1995). Magnitude of sex differences in spatial abilities: A meta-analysis and consideration of critical variables. Psychological Bulletin, 117(2), 250-270.

Wai, J., Lubinski, D. \& Benbow, C. P. (2009). Spatial ability for STEM domains: Aligning over 50years of cumulative psychological knowledge solidifies its importance. Journal of Educational Psychology, 101(4), 817-835.

Wanzel, K. R., Hamstra, S. J., Anastakis, D. J., Matsumoto, E. D., \& Cusimano, M. D. (2002). Effect of visual-spatial ability on learning of spatially-complex surgical skills. TheLancet, 359)9302), 230-231.

Weiss, E., Siedentopf, C. M., Hofer, A., Deisenhammer, E. A., Hoptman, M. J., C. Kremser, C., . . . . Delazer, M. (2003). Sex differences in brain activation pattern during a visuospatial cognitive task: a functional magnetic resonance imaging study in healthy volunteers. Neuroscience Letters, 344(3), 169-172.

Woollett, K. \&Maguire, E. A. (2001). Acquiring “the Knowledge” of London's layout drives structural brain changes. Current Biology, 21, 2109-2114.

Wright, R., Thompson, W. L., Ganis, G., Newcombe, N. S. \& Kosslyn, S. M. (2008). Training generalized spatial skills. Psychonomic Bulletin \& Review, 15 (4), 763-771. 